\title{
STUDY OF ALTERNATIVE FUELS AND EFFECTS OF COMPRESSION RATIO ON THERMAL EFFICIENCY AND ENGINE POWER
}

\author{
Sarjito \\ Mechanical Engineering Department, \\ Muhammadiyah University of Surakarta \\ Jl. A.Yani Tromol Pos I Pabelan, Kartosura \\ E-mail: sarjito_ums@yahoo.com
}

\begin{abstract}
This paper was a case study during the sabatical program at Kingston University London in February 2007. It has been studied by team of motorsport automotive department Kingston University London and it has been elaborated as a final project on Master Program. This study takes into account some of the issues surrounding the debate about alcohol fuels in Motorsport and the wider automotive sector and is primarily concerned to add data where there seems to be little existing research since Motorsport is a secretive business. Motorsport plays an important part in the automotive industry and is a sport enjoyed worldwide. Racing practice is regarded as using the best available resources and technology as it requires optimal performance. The racing arena gives engineers the opportunity to test valuable technological solutions to prove their merits. Therefore, racing is the natural starting point for introducing new technological solutions to the public and could lead to the wholesale conversion to renewable fuels to meet our automotive energy needs. Alcohol has unique properties that make superior in many ways to ordinary gasoline. The higher knock resistance allows for higher compression ratios to be utilized resulting in higher power outputs and thermal efficiency.

The efficient use of energy is of growing concern in all spheres of life and the automotive sector needs to be front runner in these efforts.
\end{abstract}

\section{Key words: Alcohol renewable fuels, thermal efficiency, Engine compression ratio}

\section{INTRODUCTION}

Problem with The most petrochemical oil: The most recent and sustained high price of oil is largely due to the fact that emerging economies are now starting to consume the oil in ever greater quantities. This is a similar scenario to the price of steel rising $60 \%$ in 9 months to furnish the building boom in Chinese cities during 2004. Now with ever increasing numbers of cars on the roads of the world, the supply of oil is not able to keep up with demand. Here in the UK, new car registrations per annum have risen steadily from 1.5 million in 1980 to 2.5 million in 2005 (www.autoindustry.co.uk).

When compared to the emerging economies of India, Brazil or China where for example, it is reported that 100,000 new registrations are made per month. Worldwide production for new 


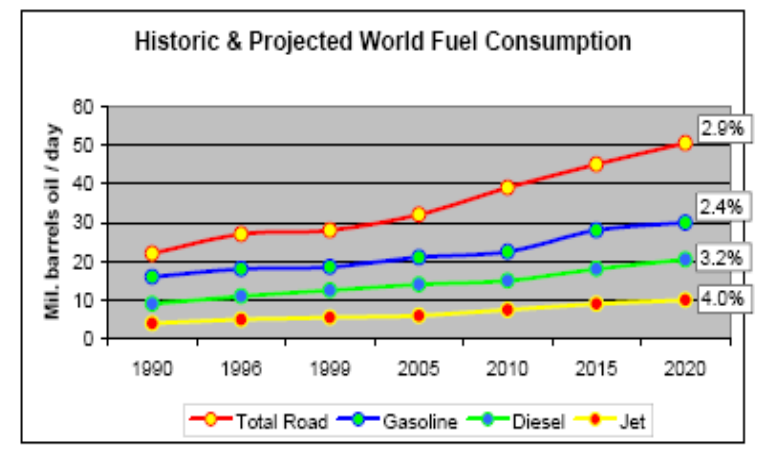

Figure 1: Historic \& Projected World Fuel Consumption Source EEMS website

cars totaled 44 millions for 2004, as compared with 39.7 million just 5 years before.

Primary production oil wells are more difficult to find, have less oil and tend to be in remote areas without good infrastructure making the logistics of transporting oil to the market more difficult. Existing wells are being phased into secondary production. Primary production is categorized by the oil coming up to the surface under its own pressure, whereas secondary production is made possible by injecting heavier water into the well to raise the level of the product. This situation is unlikely to get easier.

In addition, levels of reserves reported by the large multinational companies are to be judged with some skepticism in view of the detrimental effect that reports of rapidly diminishing reserves would have on maintaining stock share value in an already volatile financial market. The best method for finding oil is to physically drill in search of it. This process is expensive and uncertain. A most notable failure is the Muluk project in the Alaskan Beaufort Sea which cost USD\$1.5 billion of capital and found no oil reserves worth exploiting. This capital could have been spent developing Bio Ethanol infrastructure without the risk.

Furthermore, the general public is becoming increasingly aware and concerned about climate change. The causes for this have been placed squarely on the plate of fossil fuel consumption. Responsible governments have the obligation of reducing the effects of pollution and some have been bringing ever more stringent emission legislation to make vehicles cleaner. However, fossil fuels in their present form have limits on their thermal efficiency, especially since lead was phased out as an additive that increased resistance to knock allowing higher compression ratios to be run.

\section{Advantages of Alcohol}

Alternative fuels such as Bio-Ethanol and methanol are not new and apart from Brazil, South Africa and Sweden the rest of the world has not made much effort to use them until now. Bio ethanol is made from the fermentation of sugars or maize principally using stock feeds of sugar cane and corn. Being renewable it is considered to be carbon neutral since the carbon dioxide consumed by the plant as it grows is subsequently released when burnt as a fuel. Depending on the type of method used to heat the fermented liquid for final distillation, no additional energy input is required contrary to the propaganda put forward in some circles. For instance the husk of the crushed sugarcane, known as bagass, can used to fire the distillery.

Conventional engines can run on small percentages of alcohol blended with gasoline without problems but minor modification to the fuel system is needed if percentages over 20 are used.

In this way alcohol is compatible with existing automotive power plants and gives a real and viable alternative to ordinary gasoline.

\section{Rationale and Objectives}

The optimization of compression ratio was considered as an aspect to gain high engine efficiency and engine performance; however, issues of climate change are influenced by fossil fuel through the emmisions. Furthermore, possibility of alternative fuel with no environment effect should be explorated. The critical factor in this literature study is to describe vary the compression ratio while testing the ordinary and alternative fuels. Through computer simulation the resultant data should give a better overall picture of each fuels capability. 
Topics to be covered are discribing of Analyze data on power, torque, specific energy consumption, specific fuel consumption and thermal efficiency from the simulation software, in varying compression ratio using the three test fuels.

\section{Review of other similar work}

Shawn Langevin in De Freitas and D. Marchant. R. [1] noted that methanol had a high latent heat of vaporization, theoretical thermal efficiency significantly higher than petroleum and natural cooling properties which caused less $\mathrm{NO}_{\mathrm{x}}$ to be formed. However, $\mathrm{NO}_{\mathrm{x}}$ increased when the compression ratio was increased and the best ratio was identified as $6.4: 1$ air to methanol to keep $\mathrm{NO}_{\mathrm{x}}$ emissions lower then gasoline.

Langevin also found that thermal efficiency of ethanol was improved with a higher compression ratio due to it having a higher octane rating than petroleum. Like Matthew Brusstar, he confirmed that ethanol performed better under turbocharged conditions provided that sufficient load was also added.

Tabel 1: Emission Improvements of Various Mixtures Compared to Gasoline

\begin{tabular}{|c|c|c|}
\hline Bio-Fuel & Emissions & \\
\hline Methanol & 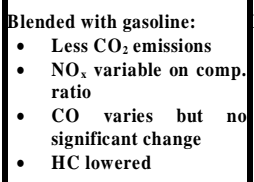 & $\begin{array}{l}\text { Blended with Diesel: } \\
\text { - Less particulates } \\
\text { - Less } \mathrm{NO}_{x} \\
\text { - Less } \mathrm{HC} \\
\text { - } \mathrm{CO} \text { is variable no significant } \\
\text { change }\end{array}$ \\
\hline Ethanol & \begin{tabular}{|l|} 
Blended with Gasoline: \\
$\begin{array}{l}\text { - Less CO2 } \\
\text { - Less HC } \\
\text { - CO and NOx are } \\
\text { variable but no } \\
\text { significant change }\end{array}$ \\
\end{tabular} & 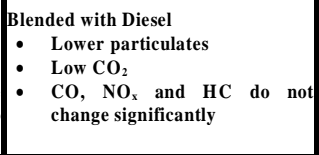 \\
\hline Bio-Diesel & $\begin{array}{ll}\text { Modified Bio-Diesel: } \\
: \quad \text { NOx increased } \\
: \quad \text { HC decreased } \\
\cdot \quad & \text { CO decreased }\end{array}$ & 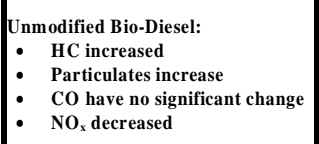 \\
\hline
\end{tabular}

There has also been supported by J W G Turner, R J Pearson, and S A Kenchington paper is with a view to finding suitable engines to reduce the $\mathrm{CO}_{2}$ emissions. Areas for improvement included reducing energy lost via heat transfer to cylinder walls, exhaust system and friction in the form of pumping work.

Among the methods put forward are lean burn homogenous charge engines operating without throttles. They concluded that his type of setup using stratified charge combustion systems reduced the pumping and increased the thermal dynamic efficient by increasing the ration of specific heats. This reduced the heat transferred to cylinder walls. However, regions within the combustion volume of a stratified charge being undiluted high flamed temperatures led to increased $\mathrm{NO}_{\mathrm{x}}$ emissions.

This set up was found to be superior to stratified wall air guided engines. However, emerging technology could reverse this situation. They also highly rated the benefits of variable compression ratio engines and deduced that in the range of 9.5:1 and 11.1 fuel economy improves by 3\% per half ratio at 2000RPM and 2 bar BMEP. Low compression ratios lead to high exhaust gas temperature and enforced induction engines; this can only be cooled by using extra fuel. The greatest benefit of varying compression ratio engines comes from those that have forced induction. This allows for optimisation of fuelling maps for low speed low load right through to high speed high load. Another method of lowering CO pollution suggested is the varying compression ratio and hence the thermal efficiency by employing a mechanism to vary the timing of IVC, On the other hand precise timing of EVO can be used across the speed/ load range to balance the expansion of gases that produce work and the release of gases under combustion to reduce pumping losses (IMechE Paper, 2005 JER03504).

Hu et al [1] investigated CI engines running on dimethyl ether using homogenous charge CI ignition. The varying compression ration from 8:1, 10.7:1 to $14: 1$ by enlarging the combustion chamber on the piston head. They found that the best thermal efficiencies were achieved at a compression ratio of $10.7: 1$. At this condition also the engine gave the widest stable working 
performance. It was also found that the increasing the combustion ratio produced advanced ignition and energy relates rates.
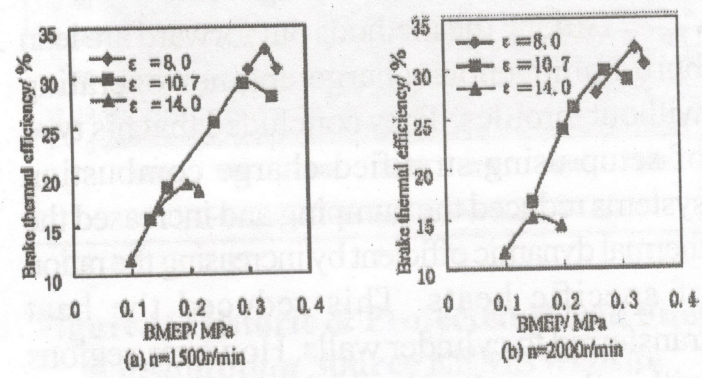

Figures 2: Brake Thermal Efficiency of the DME HCCI Engine under Different CR

They were able to control $\mathrm{NO}_{\mathrm{x}}$ emissions due to the low temperature combustion resulting from HCCI strategies with lean mixtures (SAE Paper 990619).

Michael D. Gerty of MIT had John Hayward as project supervisor for this reason this author wants to have confidence in the findings made in this paper concerning the point at whichmaximum efficiency occurs. Gerty found that in four types of SI engines maximum efficiency occurs around the middle of the RPM range. The conclusions of this paper also find this to be the case. Reducing efficiencies at lower speeds than this range is attributed to the increased time for heat transfer into the cylinder head and walls. At speeds above this range reduced efficiency can be attributed to the friction BMEP rising experientially.
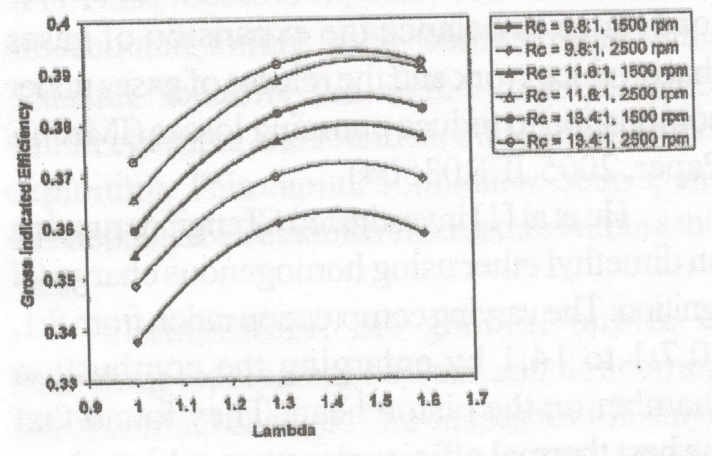

Figure 3: Change of Gross Efficiency with Lambda, 4.0barNIMEP
Among the many graphs is this one that would be of some use should the further work recommended in this paper be carried out. This paper also concluded that combustion ratios in naturally aspirated engines mostly benefits low speed torque. At higher speeds ignition retard necessary to avoid knock prevent increased gains in torque to be realised. A trade off is therefore necessary between low speed and high speed performance (MIT B.A.Cc Mechanical Engineering Paper in De Freitas and Denis R.M., 2006).

IMechE Paper 2005 D09604 by Qi et al [1] based on their experiments around a spark ignition engine with a compression ratio of 7.4:1. Their experiments looked at blending alcohols with fuel in order to access the critical phase separation temperature. They discovered a tendency for high unburnt fractions of alcohol fuel at low loads. Taljaard et al concluded that alcohol produced less $\mathrm{HC}, \mathrm{CO}, \mathrm{NO}_{\mathrm{x}}$ emissions and gasoline at Stoichiometric air fuel ratios. Other research they looked at showed a tendency for alcohol fuels to produce emissions high in formaldehyde, acetaldehyde and acetone. However, acetaldehyde is less of a problem for air quality when compared to polynuclear aromatics that gasoline engines emit in abundance. They confirmed that $\mathrm{HC}$ emissions decrease as alcohol content in the blend increased, this was also the case for $\mathrm{NO}_{\mathrm{x}}$ They also looked at the effect of alcohols on rubber in the engine fuelling system and found that it would increase rubber components mass thus constricting inner diameters eventually rendering it useless as a seal and leading to constriction of flow within fuel hoses. They found fluorocarbon carbon rubber to have good resistance to alcohols.

Matthew Brusstar et al [2-3] tested an engine similar in specification to the one presented in this paper using a combustion ratio of 19.5:1, while using EGR to suppress knock, they burnt ethanol at Stoichiometric values to achieve good emissions. They demonstrate that this configuration can give brake thermal efficiency of over $40 \%$ over a wide operating speed range. Methanol is shown to be the most 
efficient with ethanol and the turbocharged diesel engine giving similar performance.
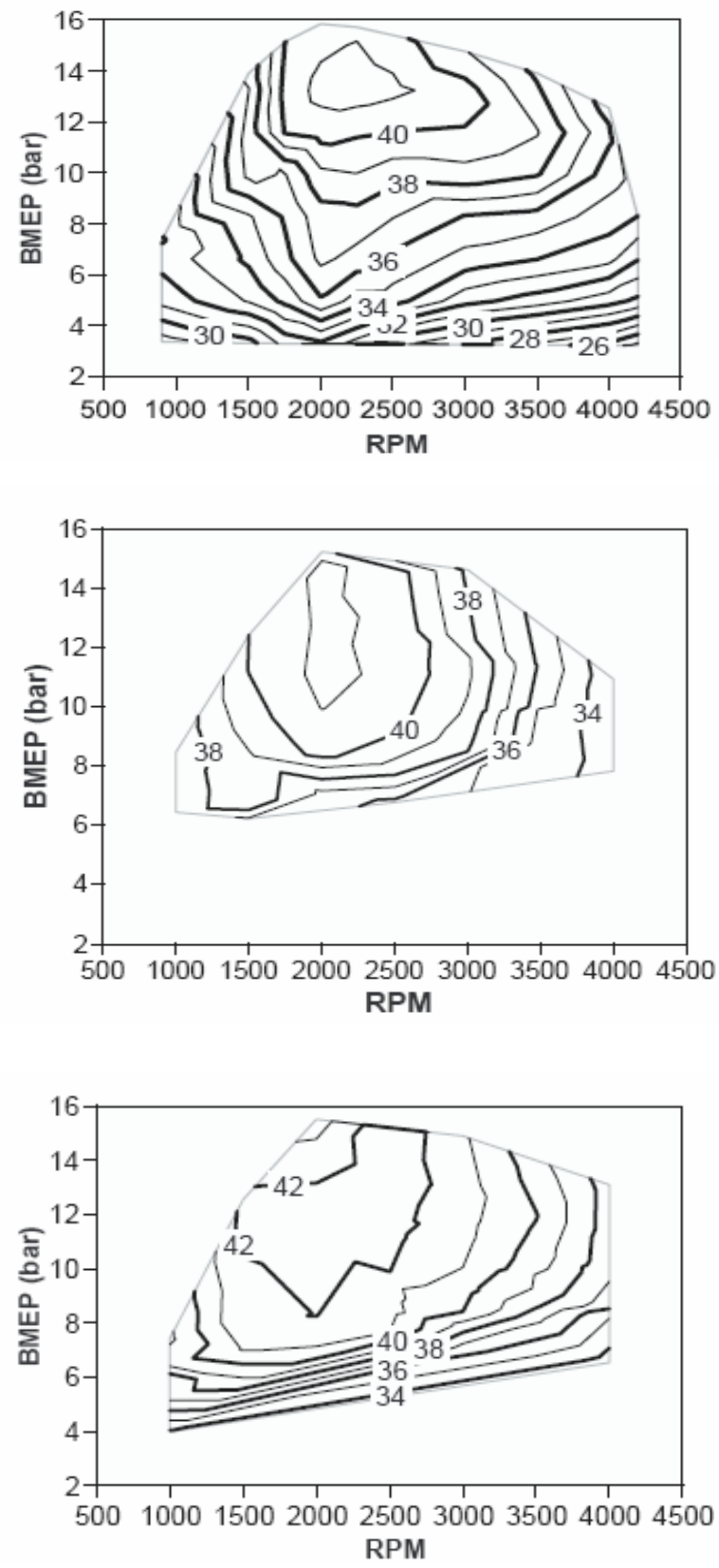

\section{Figures 4: Break Mean Effective Pressure/RPM testing of Ethanol, Methanol and Diesel with Brake thermal efficiency contours.}

S. Scott Goldsborough and Peter Van Blarigan [4] Noted in Multi-dimensional, 0D and 1D modeling, and single step parametric variations have been used to analyze and optimize the scavenging system for a free piston enginegenerator, in order to ensure high efficiency operation with low output emissions. KIVA-3V was employed, along with models for the compressor and friction processes. A range of design options was investigated including the use of loop, hybrid-loop and uniflow scavenging methods, different charge delivery options, and various operating schemes. The postprocessing software, Ensight, allowed the in-cylinder and port dynamics to be visualized and more thoroughly understood. Using these tools, the overall array of design possibilities was significantly narrowed, while some interesting configurations were explored. The results of the analyses indicated that the loop and hybrid-loop methods as investigated here cannot achieve sufficient scavenging performance, while the uniflow method, although it increases the mechanical complexity of the engine, yields the most desirable scavenging characteristics. As calculated, an optimal The results of the analyses indicated that the loop and hybrid-loop methods as investigated here, cannot achieve sufficient scavenging performance, while the uniflow method, although it increases the mechanical complexity of the engine, yields the most desirable scavenging characteristics. As calculated, an optimal arrangement employs a stratified scavenging scheme supplied by a steady, low temperature/pressure ( 300K/1.2bar) charge. The highest possible thermal efficiency should result; however, control of fuel shortcircuiting emissions, especially over small variations in the engine's operating frequency, may prove challenging. In addition, the means of supplying the fuel (carburetor or port injection) has not been addressed, and this will require additional study. On the other hand, this configuration seems to be capable of providing adequate mixing during scavenging and compression to enable rapid, TDC HCCI combustion, while maintaining efficient performance as the operating conditions vary slightly. It was seen that the incylinder flow characteristics, resulting from the scavenging process can significantly affect the operating performance. 
The KIVA-3V calculations suggested that in the pre-mixed HCCI operating mode, with low $\ddot{o}$ and moderate çsc, the production of NOx is more dependent on hot residual initiated preignition and subsequent over-compression, than on the combustion of fuel-rich regions within the cylinder. In addition, changes in the flow patterns with frequency variation can lead to large I ncreases in the short-circuiting emissions. Without adequate control, these losses may become unacceptable. One option to limit this may be to utilize low pressure, port injection, late in the scavenging cycle, in combination with a uniform intake manifold geometry. Theinjection timing and duration could be dynamically adjusted depending on the operating conditions, and as a result shortcircuiting emissions may be better managed.

\section{METHODOLOGY}

The methodology was starting from engine selection to race fundamental, calculation of friction in engine and indicates of bore and stroke relationship, connecting road, combustion chamber, compression ratio and valve configuration as well as fueling system. Further work was engine blueprinting and preparation. Principally, the author's affiliation to General Motors (GM) narrowed down the choices to one manufacturer. Then a survey was conducted of all the engines they produced in the recent past. A fairly modern engine that could be sourced fairly cheaply, second hand, was decided appropriate for the budget. The dynamometer to be used is only rated to $260 \mathrm{BHP}$ so the engine size needed to be kept on the smaller size.

After in depth discussions with championship winning engine tuner, Martin Bowyer, the X18XE1 Ecotec engine from GM was selected. The XE1 was in production from 1999 to 2003 and proved itself to be an engine with excellent emissions characteristics, good low speed torque capability and good fuel efficiency.

\section{RESULTS, DISCUSSION AND CON- CLUSION}

There is little doubt that power increases with compression ratio but thermal efficiency does not seem to. Power increase come into effect later in the rev band and would be a great additional boost any race team would be glad for. Whether the mid range band (4000 to 5000 RPM) of higher thermally efficiency can be tuned to come online later on, say between 6000 and 7000 this would make a good case for race engines nearly always operating at maximum efficiency. Since race engine spend most of their working cycle at the top of the rev range it would only be necessary to have the best efficiency there. Further simulations and a better dissection of the mathematical formulas could produce this result.

Two other deficiencies of this version of the software exist.

1. The inability to model and move the ignition point to better tune the engine model

2. There is no way of telling if indeed the engine is experiencing knock. For instance, simulations were run with gasoline fuel running at compression ration of 14:1 but it is an established fact that gasoline cannot do this without sever knock or massively advanced ignition. Therefore there is no way of ascertaining the optimal compression ratio with this software. This is a shame and physical testing is necessary. However, the software can help with engine development in conjunction with physical testing. Its superb ability to workout air flow from the careful modelling of the intake and exhaust systems allows for optimal manifold lengths to be worked out thus reducing the need to make many manifolds. On this front the change in position of the injector and the shape originally cast leaves little doubt that this camel's hump half way between the position of the racing injector and the valve needs to be filled in. At least the drawing made in Solid Works should be processed in a fluid dynamics package to verify the best model to take forward to the flow bench.

These additional tweaks are what race engine development is all about. Further work with the heat transfer coefficients would yield 
more accurate results and maybe simple laboratory experiments to find out how much methanol can cool the inlet tract and incoming air would be of some help. The change in density of the air will significantly change both the power and Thermal efficiency (TE) as a cooler charge could lead to cooler combustion. Having said that, it is surprising that the 'finger' of TE in all the simulated models is not higher up the rev band. As an engine runs higher up toward its maximum power point the temperature of the coolant increases and at some point there should be saturation and a decreased amount of time the heat can transfer into the cylinder walls and head. With this in mind, pursuing the tuning of the TE band toward the full power range may be possible but really depends on getting all the fuel to burn in that short space of time. Perhaps this is why the TE decreases high up.

Most encouraging is the flow bench verification of the simulated power figures as well as those using Heywood's data. FlowCom being an American company have experience with methanol as a fuel. The results were almost exactly the same as those given by the simulation.

With increased power potential alcohol fuels will naturally move into Motorsport. Any fuel with enhance anti-knock capability would. But Bio ethanol and natural methanol have other benefits. Benefits that the distillers and distributors of the 'new fuel' want to get into the public domain. Motor racing is a natural place to start. Many in the public enjoy racing and regard racing technology as being the ultimate in performance.

Both the alcohol fuels tested give better energy efficiency after the air fuel ratios possible are factored in. The whole world needs to look carefully at their energy consumption and that goes hand in hand with energy efficiency. Refrigerators and light bulbs often come with stickers showing their energy efficiency and car and fuel should be the same.

Alcohol fuels need to be shown to be more efficient with added environmental benefits and the terms like miles per gallon, specific fuel consumption need to be replaced with ' $\mathrm{Mj}$ per mile' and 'specific energy consumption'.

In this way the fuels can be compared on a truly level playing field.

However, currently car manufactures are making a compromise and are only making so called Flex fuel cars. This is a compromise so that they can still run on ordinary petrol. The real benefit of alcohol is it ability to run at higher compression ratios and produce more power with the same amount of fuel. In Brazil, where they have been running 'alcool' since the 1960's there is still this compromise. Not until engines are manufactured or in the case of racing allowed to run higher $\mathrm{CR}$ can the true benefits be realised. Once that step is made there will be no looking back. With only 11 petrol stations presently unless the big oil companies go into a price war to suppress it there is little doubt that these fuels will eventually take a good share of the market.

The public is conscious of environmental issues and many would like to know that they are using a fuel that is carbon neutral, coming from totally renewable sources. The economic benefits for rural and Third World economies to generate income will help alleviate poverty and givea certain degree of self sufficiency to individual countries. Why transport oil thousands of miles when you can grow it in you back garden?

Hopefully racing will promote E-85 and show it to be an excellent product. Hopefully the oil companies will not smother it renewed resurgence. This fuel is not the cure all to the energy woes we currently face but this author feels and good stepping stone to carry us until the real dream is realised.

\section{ACKNOWLEDGEMENTS}

This paper was supported by director of post graduate program automotive engineering, faculty of engineering Kingston University. Supervision of the monitoring research was carried out by Mr. Marchant. 


\section{REFERENCES}

De Freitas, C.C. and Marchant, D., 2006, Effects of Compression Ratio on Thermal Efficiency and Power Using Alternative Fuels, M.Sc. Thesis, Automotive Engineering, Kingston University, London

Brusstar, M., et al, 2002, High Efficiency and Low Emissions from a Port-Injected Engine with Neat Alcohol Fuels, sae-2002-01-2743-v2.pdf, U. S. Environmental Protection Agency

Brusstar, M. and Bakenhus, M., 2006, Economical, High-Efficiency Engine Technologies for Alcohol Fuels, National Vehicle and Fuel Emissions Laboratory, epa-fev-isaf-no55.pdf, U. S. Environmental Protection Agency

Goldsborough, S. S. and Blarigan, P. V., 2003, Optimizing the Scavenging System for a TwoStroke Cycle, Free Piston Engine for High Efficiency and Low Emissions: A Computational Approach, International Multidimensional Engine Modeling User's Group Meeting at the SAE Congress, Sandia National Laboratories. 